\section{Microwave heating and acid leaching processes for recovery of gold and other precious metals from e-waste}

\author{
Rajendra Prasad Mahapatra ${ }^{1, *}$, \\ Satya Sai Srikant ${ }^{2}$, Raghupatruni Bhima Rao $^{3}$ \\ and Bijayananda Mohanty ${ }^{1}$ \\ ${ }^{1}$ National Institute of Technology, Mizoram 796 012, India \\ ${ }^{2}$ SRM Institute of Science and Technology, Modinagar 201 204, India \\ ${ }^{3}$ CSIR-Institute of Minerals and Materials Technology, \\ Bhubaneswar 751013 , India
}

\begin{abstract}
The main aim of the present study is to develop a new method to recover gold and other precious metals such as copper, silver, etc. with the judicious combination of microwave heating and acid leaching of e-waste samples like printed circuit board of computers, mobiles, electronic devices, etc. In the present study, microwave heating is much required for segregation of melted plastics and metals from e-waste and it also generates high temperature in much lesser time. The investigation basically consists of seven stages, i.e. heating the e-waste using microwave energy, grinding, physical separation of molten plastics and metal slag followed by leaching in nitric acid, leaching in aqua regia for unreacted materials, removing with concentrated nitric acid and washing and purifying the metal deposits. The results obtained from XRD, FESEMEDAX and TEM studies confirm that precious metals like gold and silver can be obtained with the new method, which is also an environmental friendly approach.
\end{abstract}

Keywords: Aqua leaching, EDAX, e-waste sample, FESEM, image mapping, microwave heating, TEM, XRD.

IN the 21 st century, the utilization and production of electronic materials, both for business as well as household purposes in both developed and developing countries, have expanded exponentially due to which problems of piling electronic waste (e-waste) are growing everyday. In other words, it creates a huge quantity of waste in the form of obsolete electrical and electronic products (ewaste). Low prices along with new technologies innovation and addition of new features are few reasons for the replacement of electronic products at a quicker rate. E-waste is chemically and physically different from other forms of municipal or industrial waste; it contains both valuable and harmful materials that require special handling and recycling processes to avoid environmental pollution/contamination and hazardous effects on human health $^{1,2}$. Handling of e-waste is a tedious and challenging task with hazardous effects to all living beings ${ }^{3,4}$.

\footnotetext{
*For correspondence. (e-mail: mahapatra.rp@gmail.com)
}

Recovering precious metals from e-waste through hydrometallurgical processes ${ }^{5}$ along with heating is more attractive economically than other methods.

The recovery of precious metals such as gold and silver from e-waste with leaching processes involves either heating with muffle furnace followed by leaching or plasma method coupled with leaching. There are several publications and presentations on this aspect ${ }^{6-12}$. However, so far no attempt has been made on the use of microwave energy for segregation of melted plastics and metals from e-waste at lesser time and temperature compared to conventional muffle furnace. Srikant et al. ${ }^{13}$ carried out investigations with microwave heating of low grade ilmenite sample for up to $60 \mathrm{~min}$ to produce titanium product in the form of titania slag with low rich grade of $76.5 \%$. They also upgraded titania rich slag to the grade of $80-85 \%$ from $76.5 \%$ with microwave heating after addition of an extra 5\% graphitic carbon to low grade titania slag sample ${ }^{13}$. The addition of graphitic carbon played a triple role as reductant, source of heat, as well as the addition of carbon to slag. Such characteristics and products were only achieved with microwave heating but could not be achieved at less time and energy efficiency with either plasma method or with conventional heating method because, plasma method required lot of energy and conventional methods required longer time. Moreover the characteristics were not as perfect as the characteristics of microwave heating. These reasons prompted the present investigation with the effect of judicious combinations of microwave heat treatment and leaching processes on recovery of precious metals from e-waste.

Electronic materials like electrolyte capacitors, batteries, small transformers and plastics were recovered from scrapped printed circuit boards (PCB) of old computers and mobiles. However, some metal wires and epoxy base plates were difficult to recover from circuits. Hence an attempt was made to recover them by using sharp tools like cutters and nose pliers. The PCB samples with integrated chips (ICs) and pogo pins after dismantling/ removal/recovery by cutter, were used as raw materials for our present investigation to extract gold. The ICs and pogo pins removed from scrapped boards were first shredded into fragments of approximately $10 \mathrm{~mm} \times$ $10 \mathrm{~mm}$ and these fragmented samples were finally ground to a fine particle state of approximately $250-300 \mu \mathrm{m}$ (i.e. 50-60 mesh) in the laboratory.

The following methodologies were used to recover precious metals from e-waste samples.

Around $20 \mathrm{~kg}$ of ground PCBs (e-waste materials) was kept in a quartz container and mixed with $500 \mathrm{~g}$ of silicon carbide powder (with 400 mesh size). The silicon carbide powder in crushed PCB acts as a coupling agent and hence accelerates microwave heating. Some metal oxides present in crushed samples are basically low loss factors and hence poor receptors to microwave heat treatment. 
But once the carbon component is added, it acts as a good receptor to microwave heat treatment ${ }^{14,15}$. The arrangement of microwave heat treatment is shown in Figure 1. The sample with $3 \mathrm{KW}$ (i.e. $1.5 \mathrm{KW}$ both vertically as well as horizontally) produces a temperature of around $1100^{\circ} \mathrm{C}$. The presence of silicon carbide ( $\left.\mathrm{SiC}\right)$ susceptor further enhanced the heating process rapidly directly or indirectly ${ }^{14-17}$, due to which the temperature reached the range $1450-1600^{\circ} \mathrm{C}$. An adequate argon gas (inert gas) pressure as shown in Figure 1, was maintained for the microwave sintering furnace to avoid any type of oxidation reaction ${ }^{15-17}$. The container consisting of e-waste crushed samples in the microwave furnace was kept on an alumina platform as shown in Figure 2. The e-waste sample was heated for 45 min with time intervals. The product so obtained was in the form of a mixture containing metal and non-metal (more of ash), of which the metallic part could be separated easily.

The separated metallic sample obtained from microwave furnace was first cooled and then subjected to

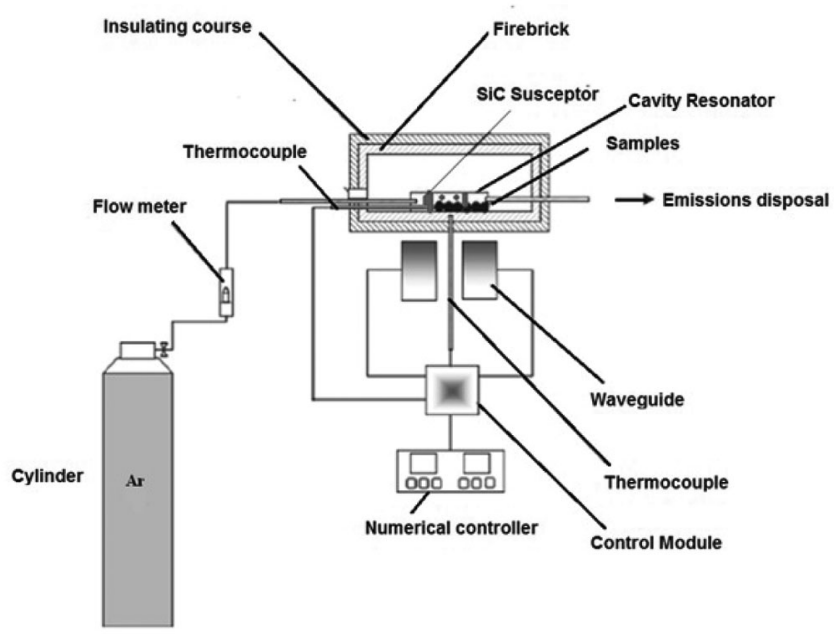

Figure 1. An arrangement of microwave heat treatment for e-waste sample.



Figure 2. Schematic sketch for crushed sample placed inside the microwave furnace for microwave heating. acid leaching studies with concentrated hydrochloric acid $(\mathrm{HCl})$. The amount of concentrated $\mathrm{HCl}$ required to solubilize metal values was calculated on the basis of stoichiometric calculations (i.e. $10 \mathrm{ml}$ of $1.6 \%$ acid solution of approximately $3.5 \%$ grade of $\mathrm{HCl}$ acid was required for $10 \mathrm{~g}$ of metallic powder sample of size less than 150$175 \mu \mathrm{m})$ of the metal values present in a typical size fraction. All leaching experiments were carried out with lab grade chemicals using $100 \mathrm{ml}$ of lixiviant at room temperature. The mechanical stirrer with a speed of around $600 \mathrm{rpm}$ was used for mixing. During leaching, hydrogen peroxide $\left(\mathrm{H}_{2} \mathrm{O}_{2}\right)$ was used as an oxidizing agent.

The unreacted sample after cementation process and other components of e-waste such as metallic pogo pins, integrated chip, transistors and diodes, etc. undergo further leaching process with aqua regia solution. The aqua regia solution was obtained with a mixture of $\mathrm{HCl}$ and nitric acid $\left(\mathrm{HNO}_{3}\right)$ in the ratio of $3: 1$ for $2 \mathrm{~h}$. But it was observed that the samples easily dissolved only in the ratio of $3.75: 1.25$ optimized aqua regia solutions (also $3: 1$ ratio). These reactions release huge bubbles followed by sublimation of nitrogen dioxide $\left(\mathrm{NO}_{2}\right)$ gas in the form of brown colour. The solution so obtained was poured into another container and the sample pieces were subsequently washed with small amount (say $10 \mathrm{ml}$ ) of concentrated $\mathrm{HCl}$. This process ensured that all the precise elements came along with the solution. A small amount $(5 \mathrm{ml})$ of sulphuric acid was further added to remove the excess $\mathrm{HNO}_{3}$ from solution and to accelerate the reactions. The estimated time to remove the $\mathrm{HNO}_{3}$ from the solution was approximately $1 \mathrm{~h}$. At this time, the colour of the solution after addition of sulphuric acid changed to pale yellow and the $\mathrm{pH}$ of the solution varied from 4.8 to 4.95 . While carrying out investigations, all precautions like wearing of face masks, safety glasses and industrial gloves should be taken to avoid any irritation or burning from the chemicals and concentrated acids. All safety measures and precautions were taken for the fumes from the burning acids that reacted with ewaste metal samples, to avoid hurting the eyes or nausea due to inhalation. During the entire experiment, pyrex glassware was also used as these containers withstand extreme heat. Plastic containers were not used as the acid can burn and damage the container.

The pale yellow mixture so obtained after optimized aqua leaching process, was stirred with a glass rod continuously until the contents became fluid. It is assumed that precise elements like gold require stronger chemicals to dissolve. Hence the aqua regia leaching process is assumed to melt all the plastic and metal parts of the circuit board without harming the gold bits. After stirring, the mixture was filtered to drain out the aqua regia solution. Upon filtering the mixture of solid parts (assumed to be gold samples) was separated from the liquid.

The mixture of solid parts, assumed to be the gold mixture was further treated for precipitation. A solution of 


\section{RESEARCH COMMUNICATIONS}

$10 \mathrm{ml}$ butyl stearate was mixed with the mixture of solid parts obtained after filtration. This solution was further mixed with $150 \mathrm{~g}$ of sodium sulphite and $1000 \mathrm{ml}$ of water. The solution was continuously stirred for $5 \mathrm{~min}$ and it was observed that the temperature rose sharply to about $80^{\circ} \mathrm{C}$. It was further observed that the gold powder rapidly precipitated from the solution. This solution was then filtered and fine gold powder was collected as the filter cake. The collected gold powder was first washed thoroughly with acetone and then with water. The gold powder sample was then dried by heating in a microwave furnace at $1 \mathrm{~kW}$ for $20 \mathrm{~min}$.

Figure 3 shows the detailed flowsheet of the entire investigation for extraction of gold from e-waste sample.

The morphological features of e-waste samples were studied after leaching and aqua regia process using field emission scanning electron microscope (FESEM). Careful investigations of e-waste sample with FESEMenergy dispersive X-ray spectroscopy (EDX) analysis along with transmission electron microscope (TEM)/ scanning electron microscope (SEM) analysis were carried out. The TEM/SEM equipment, Hitachi S-3300N has very high precision resolution of $0.10 \mathrm{~nm}$ at $300 \mathrm{kV}$. Its magnification varied from $200-500 \times$ to $2000-1500000 \times$, with AC voltage varying from 100 to $300 \mathrm{kV}$.

PANalytical X-PERT automated X-ray powder diffractometer (XRD) with Mo-K $\alpha$ radiation $(\lambda=0.709 \AA$ ) from $8^{\circ}$ to $70^{\circ}$ scanning angle at a scanning rate of $0.04 \% \mathrm{sec}$ was used for phase analysis to know the exact minerals and metals. The sample was first made in a powder form and was then kept in a sample holder for the XRD device, and the X-ray data collected at room temperature. The powder diffraction data were collected on a PHILIPS

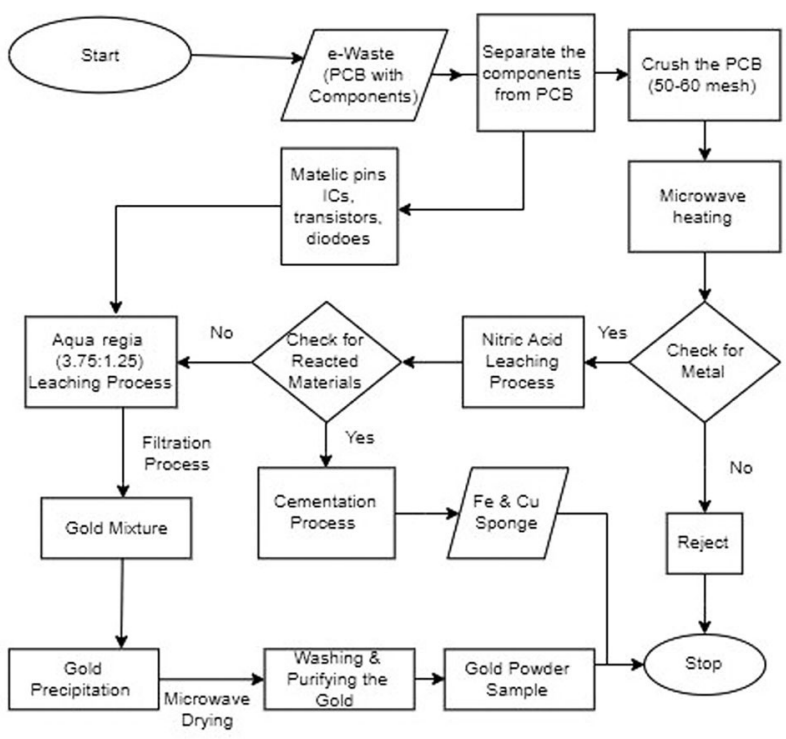

Figure 3. Flowsheet for extraction of gold from e-waste sample.
X-Pert automated XRD device. Details of parameters of XRD X-pert device are given below.

Diffractometer type

PW3710 Philips PANalytical X-PERT

Radiation Type, source X-Ray, $\mathrm{Cu}-\mathrm{K} \alpha, \lambda=0.709 \AA$

Power

$40 \mathrm{kV}, 20 \mathrm{~mA}$

Detector

Scintillation counter

Instrumental profile breadth $0.04(1)^{\circ} 2 \theta, 8-70^{\circ}$

Specimen motion Stationary

Intensity measurement Peak height

The investigations with the FESEM studies, FESEM/ EDX analysis along with TEM/EDX analysis as well as XRD studies were analysed after the treatment of e-waste samples. These studies are required for physical and chemical characterization of precious metal samples up to nano-particle wise level, obtained after e-waste treatment. Also similar investigations were performed several times to get the same results.

Around $20 \mathrm{~kg}$ of ground e-waste sample was subjected to microwave heating in a microwave furnace. The arrangement and schematic sketch are shown in Figures 1 and 2. After microwave heating, approximately $3 \mathrm{~kg}$ of metallic product was obtained and the rest was in the form of ash. The typical composition of the metallic product obtained was $\mathrm{Cu}: 55.7 \%$, Fe: $11.64 \%, \mathrm{Al}: 9.98 \%$, $\mathrm{Pb}: 0.19 \%$, Ni: $0.98 \%$, Au: $0.05 \%$ and $\mathrm{Ag}: 0.05 \%$. The typical flue gas composition was $\mathrm{CO}: 90 \mathrm{mg} / \mathrm{m}^{3}, \mathrm{NO}_{x}$ : $240 \mathrm{mg} / \mathrm{m}^{3}, \mathrm{SO}_{2}: 185 \mathrm{mg} / \mathrm{m}^{3}$, dioxins and furans: $<0.1 \mathrm{ng} /$ TEQ $\mathrm{m}^{3}, \mathrm{HCl}$ and other acidic components: $80 \mathrm{mg} / \mathrm{m}^{3}$. After passing through the scrubber and bag filter, the gas had the following composition, $\mathrm{CO}: 50 \mathrm{mg} / \mathrm{m}^{3}, \mathrm{NO}_{x}$ : $15 \mathrm{mg} / \mathrm{m}^{3}, \mathrm{SO}_{2}: 35 \mathrm{mg} / \mathrm{m}^{3}$, dioxins and furans: $<0.1 \mathrm{ng} /$ TEQ $\mathrm{m}^{3}, \mathrm{HCl}$ and other acidic components: $6 \mathrm{mg} / \mathrm{m}^{3}$. It was observed that only $275 \mathrm{~g}$ of metallic product was obtained. The specific power consumption was observed as $1.58 \mathrm{kWh}$ for $20 \mathrm{~kg}$ of e-waste processed.

The metallic portion was ground to different particle sizes such as $<150 \mu \mathrm{m}, 150-200 \mu \mathrm{m}, 250-500 \mu \mathrm{m}$ and $>500 \mu \mathrm{m}$. Leaching studies were carried out using the ground material. Very poor leaching was observed for copper with $\mathrm{HCl}$. This is because $\mathrm{Cu}$ is only leached in an oxidative environment. Since HCL is a non-oxidizing acid, it is not able to solubilize copper without an external oxidizing agent. Due to this reason, hydrogen peroxide was used. The typical composition (all in $\mathrm{g} / \mathrm{l}$ ) of the leach liquor is $\mathrm{Cu}: 23.85, \mathrm{Fe}: 1.33, \mathrm{Al}: 0.57, \mathrm{Co}: 0.17, \mathrm{Ni}$ : 0.15 . Thus it can be concluded that the leach liquor contained around $90 \% \mathrm{Cu}$. For cementation studies, iron powder was used at a stoichiometric ratio of $1: 1$. The cementation kinetics was very fast and equilibrium was achieved in $10 \mathrm{~min}$ and the efficiency was around $90 \%$. $\mathrm{Cu}$ powder obtained contained $80-85 \%$ of copper. Microstructural characterization/morphology of the metallic portion obtained after microwave heat treatment was 
carried out. The XRD result as shown in Figure 4 was analysed for those materials, which easily underwent the leaching process. The remaining unreacted materials were then treated with the aqua regia leaching process followed by filtration, precipitation and a purification process. A fine gold powder was collected as a small filter cake. The gold powder was washed thoroughly with acetone and then with water. The gold powder sample was dried by microwave heating to remove all moisture from the surface of gold samples; the remaining water diffused from the surface quickly in less time.

Copper and iron were recovered after leaching of reacted materials. This data is clearly seen from XRD analysis (Figure 4).

Since most of the copper did not form any alloy with other elements, it could be leached easily. Also since the

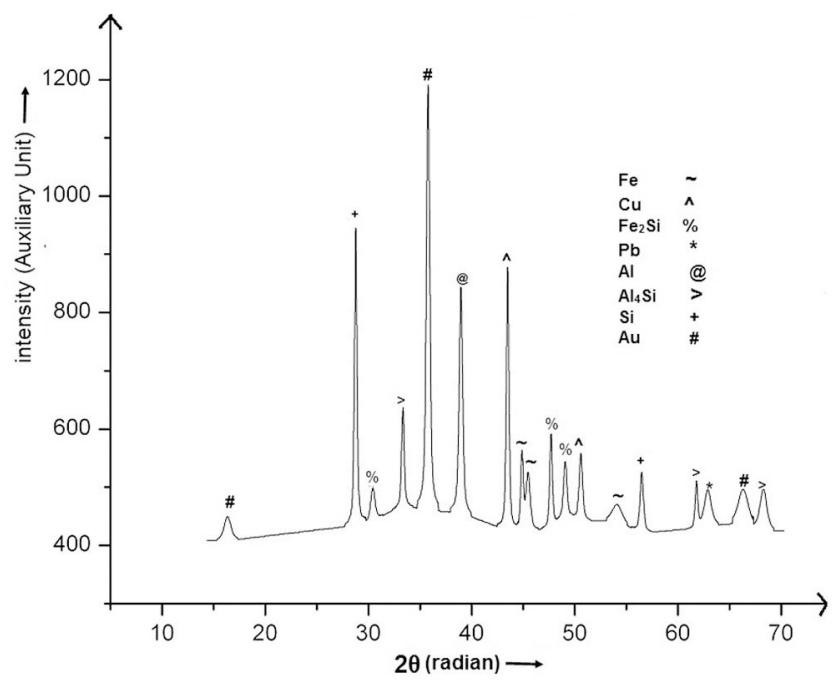

Figure 4. XRD of reacted metal after leaching process.

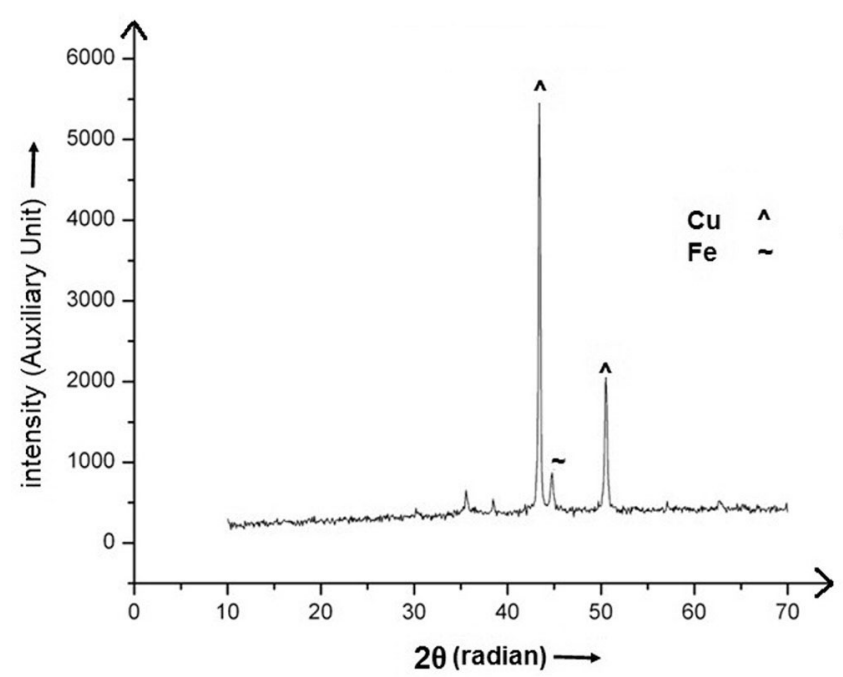

Figure 5. XRD of the copper sponge. iron (Fe) and aluminium (Al) formed alloys with each other and with $\mathrm{Si}$, they showed poor leaching efficiencies. Figure 5 shows the XRD of the copper sponge obtained from the leach liquor after cementation process, which showed copper as the major peak.

The gold mixture was obtained after the aqua leaching of unreacted materials. The XRD analysis of gold sample is shown in Figure 6 after passing through precipitation, purifying and washing the gold mixture. The mineral phase of gold sample is shown in Table 1. The FESEMEDAX analysis in Figure 7 shows the presence of gold sample and also confirms the presence of silver after the process of aqua regia leached un-reacted material. The results from TEM/EDX analysis as shown in Figure 8, also confirm the presence of gold and silver.

All the calculations carried out based on batch scale investigation are shown in Figure 9. The expenditure (as calculated in Indian currency, i.e. Rs) will further come down drastically, when work is done on a continuous scale. $\mathrm{HCl}$ cost has been taken as Rs 50/litre and hydrogen peroxide cost as Rs $200 / \mathrm{kg}$.

Thus, it is seen that good results are obtained with the judicious combination of microwave heating and acid leaching process for recovering gold and other precious metals. The entire study was performed several times for similar results. The study shows that the results after ewaste treatment are not only obtained in lesser time but also with lesser power consumption. The results so

Table 1. XRD data of gold sample

\begin{tabular}{lc}
\hline XRD mineral phase & Two theta $(2 \theta)$ \\
\hline $\mathrm{Au}=$ Gold & $15.12 ; 20.51 ; 37.42 ; 43.01 ; 64.85$ \\
$\mathrm{Ag}=$ Silver & $22.43 ; 25.34 ; 26.47 ; 44.87$ \\
\hline
\end{tabular}

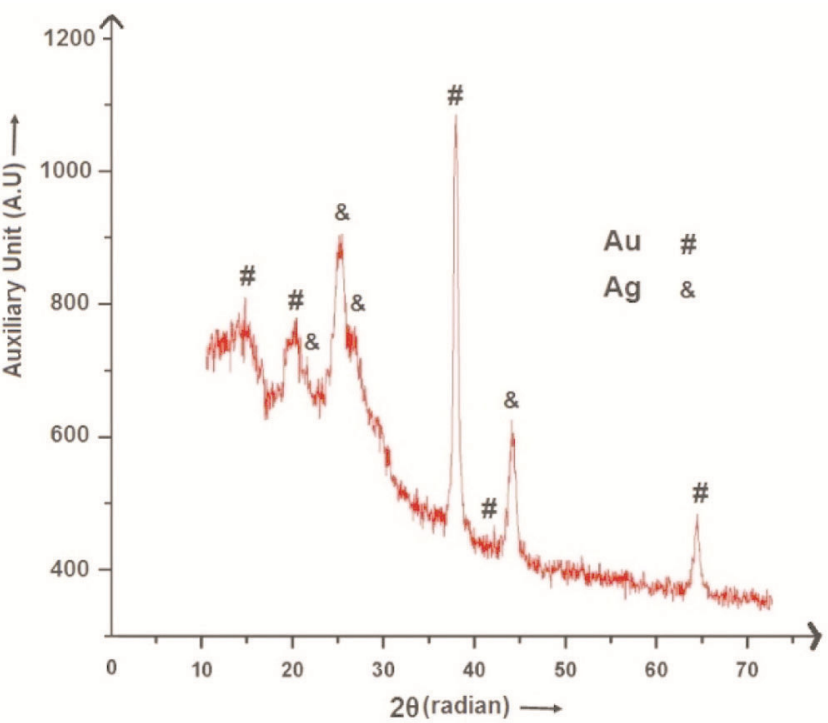

Figure 6. XRD of the gold mixture.

CURRENT SCIENCE, VOL. 116, NO. 3, 10 FEBRUARY 2019 


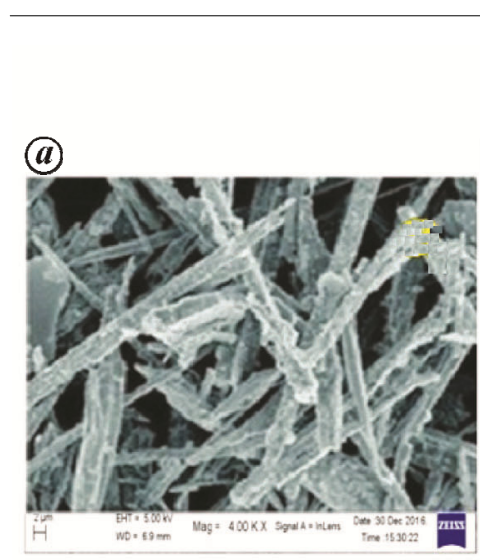

(b)
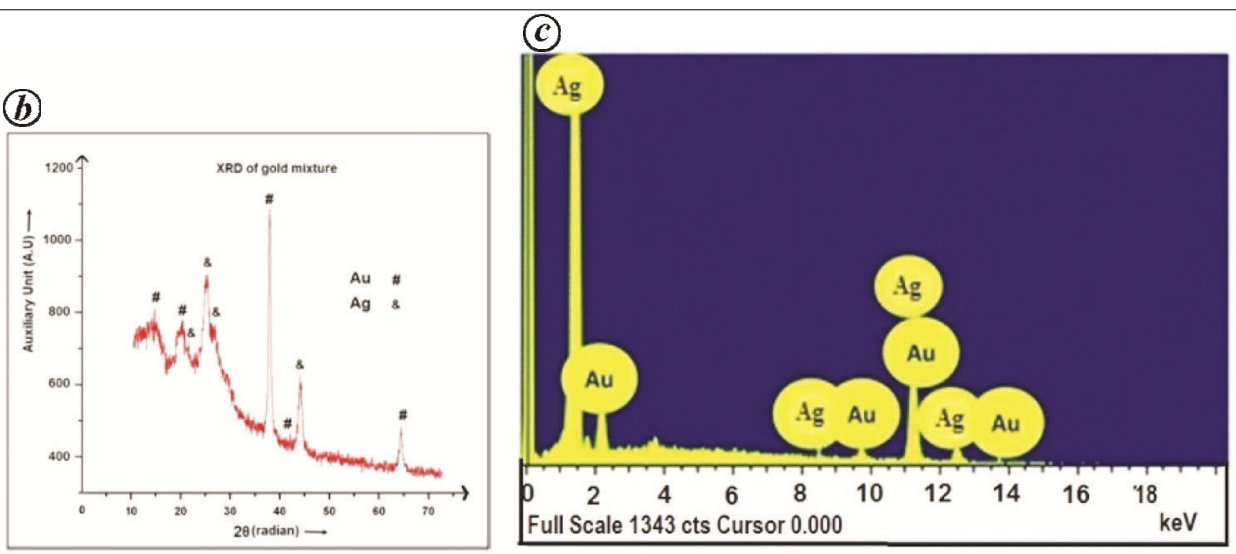

Figure 7. FESEM-EDAX analysis after aqua regia leaching process.

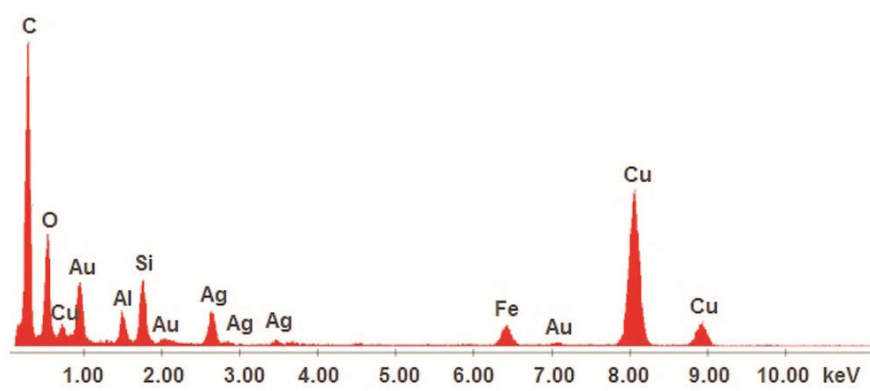

Figure 8. TEM-EDX analysis after aqua regia leaching process.

\begin{tabular}{|c|c|c|c|c|}
\hline \multicolumn{2}{|l|}{$1 \mathrm{Kg} \mathrm{E}$ waste } & Energy Consumption & $\begin{array}{l}\text { Expenditure } \\
\text { Rs. }\end{array}$ & $\begin{array}{l}\text { Approx. } \\
\text { Value, Rs. }\end{array}$ \\
\hline Mic & Microwave Treatment & $2 \mathrm{kWh} / \mathrm{Kg}$ & 6 & \\
\hline 150 g metal & \multicolumn{2}{|c|}{ Leaching with $\mathrm{HCl}$} & $\begin{array}{l}\text { Acid }: 45^{\star} \\
\mathrm{H}_{2} \mathrm{O}_{2}: 50^{*}\end{array}$ & \\
\hline $\begin{array}{l}\text { Leach liquor with } \\
\mathrm{Cu}, \mathrm{Ni} \text { and } \mathrm{Co}\end{array}$ & $\begin{array}{l}\mathrm{Cu}: 15 \mathrm{~g} \\
\mathrm{Co:} 5.5 \mathrm{~g} \\
\mathrm{Ni}: 3.1 \mathrm{~g}\end{array}$ & & & $\begin{array}{l}\mathrm{Cu}: 65 \\
\mathrm{Co}: \mathbf{5 . 5 0} \\
\mathrm{Ni}: 3.25\end{array}$ \\
\hline $\begin{array}{l}\text { Residue with } \\
\mathrm{Au} \text { and } \mathrm{Ag}\end{array}$ & $\begin{array}{l}\text { Au: } 0.15 \mathrm{~g} \\
\text { Ag: } 0.15 \mathrm{~g}\end{array}$ & & & $\begin{array}{l}\text { Au: } 300 \\
\text { Ag: } 7\end{array}$ \\
\hline \multicolumn{3}{|c|}{$\begin{array}{l}{ }^{*} \text { Cost will come down if air is used instead } \\
\text { of } \mathrm{H}_{2} \mathrm{O}_{2} \text { and commercial grade chemicals are u sed }\end{array}$} & $\begin{array}{l}\text { al expenditure } \\
\text { al value gained }\end{array}$ & $\begin{array}{l}=\operatorname{Rs} 105 \\
=\operatorname{Rs} 381\end{array}$ \\
\hline
\end{tabular}

Figure 9. Budget based on bench scale investigation.

obtained are also economical and show good physical as well as chemical characteristics. More importantly, the process is an eco-friendly as well as a clean process.

The following conclusions are drawn for the present treatment of e-waste using microwave heating followed by acid leaching.

- The hazardous ground e-waste material was heated in a microwave furnace to recover the useful metals. It is observed that microwave heating process shows good efficiency of metal recovery in solid form.

- It is also observed that microwave heating treatment generates less waste compared to conventional treatments of e-waste.

- Leaching of the metal obtained from microwave heat treatment was subjected to leaching by hydrochloric acid in stoichiometric ratio. However, it is observed that with aqua regia leaching for un-reacted materials and dismantled electronics parts, precise metals like gold and 
silver are obtained in small amounts in lab scale experiments.

- The XRD and FESEM-EDAX studies of the metallic product in the present investigation confirm the presence of gold and silver after aqua leaching of e-waste sample.

- TEM-EDX study analysis shows that leached residue also confirms the presence of gold $(\mathrm{Au})$ and silver (Ag).

- The expenditure for the present study was calculated for $1 \mathrm{~kg}$ of e-waste sample. It shows that the total value of gain product gives a gain amount Rs 381 (in Indian currency Rupees) with an expenditure of Rs 105 for performing such small experiments. However, the expenditure as well as consumption of such an experiment will certainly come down in a continuous large scale operation, which makes the process more economical. Moreover, air instead of $\mathrm{H}_{2} \mathrm{O}_{2}$ as an oxidizing agent; will also cut down the cost further.

- The entire investigation shows that microwave heat treatment is not only a clean process but also an ecofriendly process for obtaining valuable precious metals like gold and silver metals from e-waste.

1. Khanna, R., Cayumil, R., Mukherjee, P. S. and Sahajwalla, V., A novel recycling approach for transforming waste printed circuit boards into a material resource. Proc. Environ. Sci., 2014, 21, 4254.

2. Cui, J. and Zhanga, L., Metallurgical recovery of metals from electronic waste: a review. J. Hazard. Mater., 2008, 158, 228256.

3. Dey, S. and Jana, T., E-waste recycling technology patents filed in India - an analysis. J. Intell. Prop. Rights, 2014, 19, 315-324.

4. Buekens, Alfons and Jie, Y., Recycling of WEEE plastics: a review. J. Mater. Cycles Waste, 2014, 16, 415-434

5. Balde, K., The Global E-waste Monitor 2014 - Quantities, flows and resources. United Nation University; https://i.unu.edu/media/ unu.edu/news/52624/UNU-1stGlobal-E-Waste-Monitor-2014-small. pdf

6. Pant, D., Joshi, D., Manoj Upreti, K. and Ravindra, K. K., Chemical and biological extraction of metals present in e-waste: a hybrid technology. Waste Manage., 2012, 32, 979-990.

7. Chaurasia, A., Singh, K. K. and Mankhand, T. R., Extraction of tin and copper by acid leaching of PCBs. Int. J. Metall. Eng., 2013, 2(2), 243-248.

8. Bala, I. A. K. and Hassan, M. A. A., Thermal plasma treatment of wastes: a review. Aust. J. Basic Appl. Sci., 2015, 9(31), 322-333.

9. Biswajit, R., Thermal plasma treatment of mobile phone waste under reduced condition. Int. J. Environ. Sci., 2012, 2(4), 1-8.

10. Cerqueira, N., Vandensteendam, C., Baronnet, J. M. and Girold, C., Heavy metals volatility during thermal plasma vitrification of mineral waste. Environ. Eng. Sci., 2004, 21(1), 83-92.

11. Abdul, K., Rhamdhani, M. A., Brooks, G. and Syed, M., Metal extraction processes for electronic waste and existing industrial routes: a review and Australian perspective. Resources, 2014, 3, $152-179$.

12. Cheng, T. W., Chu, J. P., Tzeng, C. C. and Chen, Y. S., Treatment and recycling of incinerated ash using thermal plasma technology. Waste Manage., 22(5), 485-490.

13. Srikant, S. S., Mukherjee, P. S. and Rao, R. B., Morphological characterization of titania slag obtained from red sediment placer ilmenite using microwave energy. J. Inst. Eng. India Ser. D, 2015, 96, 43-49
14. Srikant, S. S., Mukherjee, P. S. and Rao, R. B., Prospects of microwave energy in material and mineral processing. Turk. J. Eng. Sci. Technol., 2013, 2, 23-31.

15. Pickles, C. A., Microwaves in extractive metallurgy: Part $1-\mathrm{A}$ review of fundamental. Miner. Eng., 2009, 22, 1102-1111

16. Srikant, S. S., Mukherjee, P. S. and Rao, R. B., Microwave energy for waste management. Mineral Process. Technol., 2013, 3, 948953.

17. Srikant, S. S., Mahapatra, R. P. and Laxmi, T., Microwave energy for waste used engine oil. The Institution of Engineers (India) Odisha State J., 2015, 1, 255-261.

ACKNOWLEDGEMENTS. We are grateful to the Director, Scientists and Researchers of CSIR-Institute of Minerals and Materials Technology, Bhubaneswar for extending the facilities to carry out the work and for the guidance provided. The views and opinions expressed in this paper are purely those of the authors and may not be of those who were involved during the study and preparation of the manuscript. This study did not receive any specific grant from funding agencies in the public, commercial or not-for-profit sectors.

Received 4 August 2018; revised accepted 11 October 2018

\section{Anti-inflammatory activity of synthesized diarylpentenedione derivatives and their drug delivery with silicon-nanotube $(7,7)$}

\author{
A. Surendar ${ }^{1}$, S. K. Sadulla ${ }^{1}$, Ali Noory Fajer ${ }^{2}$, \\ Mazhar Abbas ${ }^{3}$ and Meysam Najafi ${ }^{4, *}$ \\ ${ }^{1}$ School of Electronics, Vignan's Foundation for Science, \\ Technology and Research, Guntur 522 213, India \\ ${ }^{2}$ Department of Biology, Education College, \\ University of Al-Qadisiyah, Al Diwaniyah, Qadisiyyah, Iraq \\ ${ }^{3}$ Department of Management Sciences, COMSATS University, \\ Islamabad Vehari Campus, Pakistan \\ ${ }^{4}$ Medical Biology Research Center, Kermanshah University of \\ Medical Sciences, Kermanshah 67149-67346, Iran
}

Earlier studies have confirmed that diarylpentenedione derivaties $1 \mathrm{a}$ and $1 \mathrm{c}$ have the highest and the lowest anti-inflammatory activity respectively. In this work, the interactions of diarylpentenedione derivatives 1a-1c with Si-nanotube $(7,7)$ were studied and quantum molecular descriptors of the diarylpentenedione derivatives were calculated. Results showed that 1a-1c can interact with $\mathrm{Si}$-nanotube $(7,7)$ significantly and so their adsorptions were possible from an

*For correspondence. (e-mail: meysamnajafi2016@yahoo.com) 